The author's experience and ingenuity in applying $\mathrm{X}$-ray methods to localise the position of foreign bodies are so well known that when he comes forward with improved methods of electric probing, which have the distinguishing merit of the utmost simplicity, we may be sure they will find immediate and extensive application.

\section{GEODETIC SCIENCE.}

NO. 3 of the new series of professional papers of the Ordnance Survey contains some excellent notes on the geodesy of the British Isles, by Colonel Close, R.E., which bring the position of geodetic achievement fairly up to date, and incidentally add some historical indications of the processes by means of which our position in the world of geodetic science has been secured. Their usefulness has been increased by the addition of a very ample bibliography of the science, and by simple diagrams illustrating certain special features affecting geodetic levelling, including the principal triangulation of Great Britain, the geo graphical position of the West European meridional arc, and of the European longitudinal arc. In the section of the pamphlet dealing with standard measurement it is interesting to observe that the national standard yard, which was legalised in I 855 , consists of a marked length on a bronze bar bearing a definite relationship to the "international " metre (also a measured length on a bar), which was originally intended to represent one ten-millionth of the length of the earth's meridional quadrant.

Colonel Close's sketch of the various operations undertaken to determine the figure of the earth, dating from Airy's investigations of 1830 to Helmert's determination of 1906 , proves incidentally the extraordinary value of the early investigations undertaken with inferior instruments. On Airy's figure the whole of the mapping of the United Kingdom still depends, nor have the results deduced from the reduction of the principal triangulation affected the map values. In the length of 7 \%o miles from Shanklin to the extreme north of the Shetlands Airy's figure gives about four seconds in latitude too much, if we accept Helmert's figure as the criterion. This does not affect the linear accuracy of the map. Three figures were computed by Colonel Clarke (in $185^{8}$, I 866 , and 1880 respectively) from the data furnished by the reduction of the principal triangulation. They are all in use, either in Africa or America. The mean value in length determined by Clarke of the semi-axis major of the ellipse, the revolution of which about its minor axis produces the spheroid of the earth's surface, is less than that of Airy and only slightly greater than that of Helmert. Colonel Close records his opinion that the probable value is somewhat greater than Clarke's mean.

Many people must have noticed the apparently haphazard way of recording "bench" marks by the Ordnance Survey to indicate altitudes determined by levelling. They are to be found on most unNO. 2369, vOL. 95] substantial walls, on milestones, and even on gateposts, and they must, many of them, inevitably be unstable. In the section of the pamphlet dealing with levelling, Colonel Close indicates the method by which, in future, such marks will be rendered permanent. Concrete blocks will be sunk on to hard rock foundations at intervals of about twenty-five miles all over the country; a bolt of bronze, with a knob of flint being embedded in the concrete. This section is also of interest as a record of the difficulties experienced in dealing with the adopted datum of mean sea-level. Indian survey investigations have contributed largely to the solution of this troublesome problem. It is in India, too, under Colonel Sir S. Burrard, that the most comprehensive investigations have been made in the matter of the deflection of the level, and the apparent eccentricities of the force of gravity, including the difficult problems which beset the speculative subject of isostasy; but Colonel Close's references to early English methods of determining the value of deflection due to local topography are extremely interesting as a record of the first steps taken in the evolution of this special branch of geodetic science. These plain and intelligible notes on a highly complicated subject, being entirely free from any affectation of technical specialism, should attract a much wider range of scientific interest than is indicated by the title of Ordnance Survey Professional Papers. T. H. HoLdich.

\section{SCIENTIFIC FACTORS OF INDUSTRIAL SUCCESS.}

THE Institute of Industry and Commerce (now the Institute of Industry and Science), so the introductory leaflet states, is a counterpart of a German organisation known as the Hansa Bund. How the Hansa Bund arose or by whom and when it originated we have no knowledge. It is a confederation of important German firms for promoting, encouraging, and facilitating German home and foreign trade. It is proposed by similar means, but on somewhat "superior lines," to do the same for British industry, and the directors invite those interested in the development of our industries by the aid of science to enrol themselves as members. A portion of the revenue of each year is to be devoted to scientific research under the supervision of our most eminent men of science. Accompanying this leaflet are a number of brochures touching on the causes and effects of German commercial success and on the remedies for British commercial decline.

If "in the multitude of counsellors there is safety," in the diversity of their opinions there may also arise confusion. Sir W. Ramsay conceives that the main purpose of the Institute is to combat German industrial methods, which are said to be organised on a policy of dishonesty and trickery. This is to be undertaken by the State by adopting something of their methods, or by endeavouring to thwart them. Mr. S. Roy Illingworth, in his pamphet on "The Organisation 
of the Chemical Industries," advocates combination between different branches of industry, elimination of home competition, efficient advertising, the employment of highly trained chemists and engineers, reducing the cost of production, and finally some measure of protection. Sir George Watson, who also writes on "Chemistry and Industry," lays stress on the importance of highly trained chemists and the vaiue of protection or some form of financial assistance for the newer industries. Mr. J. Taylor Peddie, in his review of "British Imperialism and German Culture," points out that although German ideals have been established upon sound democratic and Christian principles, and have had a vital, sustaining, and elevating influence, these ideals have been momentarily wrecked on the rocks of feudalism, absolute monarchism, and militarism. He realises Germany's intellectual superiority, for which we have no substitute, and demands organisation unrestricted by the State, which is too much dominated by the political party system. In a second brochure on "Finance and Industry" the same writer finds Germany's great commercial progress to be primarily due to the development of its financial system, and instances the advantages which the banks offer by advancing loans to industrial undertakings.

It will be seen from this rather brief epitome that whilst the writers unite in pointing out the unsatisfactory position of our industries, especially those into which science largely enters, they are not quite unanimous, either in regard to the cause of or the remedy for the present state of affairs.

It is no doubt true that our chemical industries have in the past been hampered by absurd duties and still more absurd patent laws, and that, speaking generally, the scientific industries have received little sympathy or encouragement from any Government, past or present. It is also true that German commercial acumen, not always over scrupulous, has succeeded in wresting from us a good deal of foreign trade. In this connection we are reminded of a chapter in Bagot's "My Italian Year," in which he describes how Germans have established themselves, as well as their goods, in the larger Italian cities, and that much of the trade formerly carried on by us has passed into their hands. All this is true enough, but there is another side to the picture. Our chemical industries have failed to prosper not because Germany has had special advantages in the use of cheap alcohol, or in its patent laws, or in its financial system or in its protective tariff, but because in recent years these industries have passed into the hands of men who have had no proper chemical training.

So long as this exists the industry will be run by rule-of-thumb methods; no advance can be made, because nothing new is being discovered or manufactured; for it must be remembered that it is not the old stereotyped products, but the novelties that bring the large profits. Where can we show such a record as that of the Baden Aniline Company, which laid out a million sterling on experiments carried out by a body of highly trained and highly paid chemists working unceasingly for ten years in elaborating the process for producing artificial indigo, which has now nearly driven out the natural product?

We lack knowledge first and last, as well as enterprise and that kind of adaptability which studies to supply the needs of foreign countries, and this applies to others besides the chemical trade. We remember an old Lancashire cotton weaver, whose trade, once a thriving one, gradually fell away because he insisted on always producing the same kind of cloth long after it had ceased to be in demand, for no other reason than that he had always done so.

We could point to many other industries which to-day are languishing or disappearing for the same reason. The heads of these firms do not keep pace with the time; they do not keep up any pace at all; they stand still. They stagnate in a backwater of ignorance, unconscious of the rapidly flowing stream of scientific achievement; which must in the future be the guiding current in every branch of industry if commercial success is to be attained.

It was announced on Monday that there has been such a poor response on the part. of subscribers that the directors of the company British Dyes (Limited) do not feel justified in proceeding to allotment, and a meeting has been called to consider the situation. This state of affairs might have been anticipated from the amount of adverse criticism to which the Government scheme has been subjected. The scheme restricted competition at home, but made no attempt to safeguard future competition from abroad, and gave no guarantee in the constitution of the directorate that the industry would be conducted on a sound scientific basis. The question is still unanswered as to the best and safest means of resuscitating this moribund industry (if one may apply these terms to describe what has never been really alive for the last half-century).

Every chemist will admit that this is a problem which cannot be solved in a hurry. Owing to the complex nature of the products and the special character of the apparatus and machinery employed, a long period of patient experimenting under the control of the best chemists and chemical engineers that the country can provide will be required before success can be attained. It will naturally entail a heavy outlay in salaries and plant, and probably no profits for a long time to come. Who is going to undertake this whilst the textile industry with its millions of workpeople is starved for the want of dyes? If the country ran short of ammunition in the present crisis, the Government would at any cost be compelled to undertake its production.

The same kind of national crisis exists to-day in the dyeing industry, and the same remedy should be applied without further delay. The colour-makers have had their opportunity. They have been warned for years past what their fate would ultimately be if they neglected to develop No. 2369 , voL. 95] 
their manufacture on a scientific basis. That opportunity has gone. The only practical plan would seem to be for the Government to take the matter in hand and independently of public financial assistance to obtain its staff of expert chemists under adequate scientific control, and by their aid to work out the initial experimental stages and afterwards either manufacture the dyes or make over the processes on certain conditions to private firms.

\section{NOTES.}

WE regret to see the announcement of the death, on March 2I, in his sixty-fourth year, of Dr. A. A. W. Hubrecht, professor of embryology at the University of Utrecht.

THE honorary freedom of the Apothecaries' Company has been conferred upon Sir Ronald Ross, in recognition of the valuable services rendered by him to medical science, especially in the prevention of tropical disease.

IN recognition of their services as consulting surgeons to the British Expeditionary Force in France Mr. G. H. Makins and Sir Anthony A. Bowlby have been made Knights Commander of the Order of St. Michael and St. George (K.C.M.G.).

THE Nieuree Courant, the Hague, of March 3, states that the van't Hoff fund committee of the Academy of Sciences of Amsterdam received five applications for grants. The only one awarded was for 600 francs to Dr. E. D. Tsakalotos, of Athens, in aid of his researches on the thermal properties, the viscosity, and the magnetic susceptibility of binary mixtures, capable of yielding endothermic compounds.

AT a meeting of the executive committee of the British Science Guild, held on March 16, it was resolved to send copies of a resolution formulated by the medical committee, advocating inoculation against typhoid fever, to the commanding officers of every regiment of the British Army. Reports on the question of the supply of optical glass and of glass for chemical purposes-formerly largely obtained from Germany and Austria-showing what has already been done in these matters, were also ordered to be widely circulated. The question of the shortage of microscopes was considered, and action is being taken by the guild in this matter.

THE death is announced, after a short illness, of Prof. W. Smart, professor of political economy at Glasgow University. Prof. Smart began his academic work in I886 as lecturer on economics at University College, Dundee, and Queen Margaret College, Glasgow. On the affiliation of Queen Margaret College to the University, he became University lecturer on economics, and in 1896 was appointed to the Adam Smith chair of political economy. In addition to his professorial work, Prof. Smart translated BöhmBawerk's "Capital and Interest" and "Positive Theory of Capital," edited Wieser's " Natural Value," and compiled "Economic Annals of the Nineteenth Century." Among his other works are "Taxation of Land Values" and "The Return to Protection."

$$
\text { NO. 2369, voL. 95] }
$$

THE Geologists' Association has made arrangements for an excursion to Glasgow from April 2 to April 8. The object of the excursion is to examine the geology of the district around Glasgow. On April 2 Prof. J. W. Gregory will conduct the party around the Campsie Fells. On April 3 South Bute will be visited under the directorship of Mr. W. R. Smellie. Garabal Hill, Loch Long, and Loch Lomond will be studied on April 5 under the guidance of Mr. A. Scott; the Falls of Clyde, Cartland Gorge, and Kames of Carstairs on April 6, when Prof. J. W. Gregory and Mr. J. Stark will direct; Lugar and Mauchline on April 7, director, Mr. G. W. Tyrrell; Hamilton Park and Strathaven on April 8, directors, Messrs. Macintyre and Carruthers. Intending visitors should communicate with the secretary for the excursion, Miss G. M. Bauer, I6 Selborne Road, Handsworth Wood, Birmingham, from whom particulars as to trains and accommodation can be obtained.

THE death has occurred at Dartmouth, at the age of eighty-six, of Mr. E. W. H. Holdsworth, who will be remembered by his book, "Deep-Sea Fishing and Fishing Boats," published in 1874 , which gives the best and most intelligent account of the British fisheries at that time which we possess. This book will always be of the first importance to those interested in the progress and development of our sea fisheries. $\mathrm{Mr}$. Holdsworth wtote from great personal knowledge of the subject, as he had acted as secretary to the Royal Commission, of which Prof. Huxley was a member, which between 1863 and 1865 travelled all around the British coasts inquiring into the condition of the fisheries. At the close of the work of this Royal Commission, Mr. Holdsworth went for some years to Ceylon in order to conduct an official inquiry into the pearl fisheries. In $188_{3} \mathrm{Mr}$. Holdsworth took an active part in the International Fisheries Exhibition and contributed to the literature of that exhibition an important paper on apparatus for fishing. On the foundation of the Marine Biological Association he was for some years a member of the council. Previous to his work in connection with the fisheries Mr. Holdsworth took part in the management of the Zoological Gardens, Regent's Park, and the Proceedings of the Zoological Society contain several papers which he wrote, chiefly on anemones and corals.

Mr. J. S. MacArthur, whose name is well known in connection with the cyanide process of extracting gold, has been engaged during the past two years in the extraction of radium from carnotite and similar ores at his factory at Runcorn. From a statement in the Press we learn that Dalvait, Loch Lomondside, has been selected as the site for a new factory, on account of the advantages offered by the purer air and water supply in this neighbourhood. The new factory is to deal with between five and six 'grams of radium annually, and will be a welcome addition to the country's sources of radio-active materials. Hitherto, with the exception of one concern, working up the pitchblende from the Trenwith mine, Cornwall, this country has been entirely dependent upon foreign radium. The output of another. Cornish pitchblende mine is sent to France to be extracted, and the re- 